\title{
Orta Asya Türk Ülkeleri ve Türkiye'de Zamanlararası Dış Bütçe Kısıtının Ekonometrik Analizi
}

\author{
Econometric Analysis of Intertemporal External Budget \\ Deficits in Central Asian Turkic Countries and Turkey
}

\author{
Doç. Dr. Sabri Azgün
}

\section{Öz}

Ekonomiler, sürdürülebilir ekonomik büyüme ve gelişmelerini gerçekleştirebilmek için, ödemeler dengesi açıklarına dikkat etmek durumundadırlar. Bir ülkenin cari işlemler açıkları bakımından risk taşıması, cari ekonomi politikasinin hali hazırda ve gelecekte sürdürülebilirlik noktasında sorunlu olduğunun göstergesi olarak değerlendirilebilir. Cari işlemler açı̆̆ının sürdürülebilirliği, zamanlararası bütçe kısıtına bağlı olarak tanımlanmaktadır. Söz konusu dış bütçe kısıtına göre, $d$ ş dünyadan elde edilen gelirler ile diş âleme yapilan ödemelerin izleyeceği yol, zamanlararası geri ödeme yeteneği koşulunu belirlemektedir. Eğer bu iki değişken arasinda uzun dönem denge ilişkisi mevcut değilse, zamanlararası bütçe kısıtı sağlanmaz. Bu çalışmanın amacı, 2005Q1-2014Q4 dönemi için Orta Asya Türk Ülkeleri ve Türkiyennin zamanlararası geri ödeme yeteneği koşulunu sağlayıp sağlamadığın belirlemektir. Bu çalışmada, söz konusu Avrasya ekonomilerinin cari işlemler dengesi açısından potansiyel risk taşıyı taşımadı̆̆ incelenmişstir.

Anahtar Kelimeler: Cari İşlemler Açıkları, Geri Ödeme Yeteneği, Orta Asya Türk Ülkeleri

\begin{abstract}
Economies should pay attention to the deficits of the balance of payments in order to achieve a sustainable economic growth and development. A country having risks in terms of current account deficits can be evaluated as the current economic policy is having problems
\end{abstract}

at present and will have in days to come in the point of sustainability. The sustainability of the current account deficits are defined by the intertemporal budget constraint. According to the budget constraints, the path of outlays to the external world with revenues obtained from abroad determines intertemporal solvency contidion. If there is no long-run equilibrium relationship between these two variables, intertemporal budget constaint will not be provided. The aim of this study is to determine whether it satisfies the intertemporal solvency condition of Euorasian economies for the period 2005Q1-2014Q4. In this study, it is examined that carries potantieal risk in terms of the current account balance of the Euroasian economies.

Keywords: Current Account Deficits, Solvency, Central Asian Turkic Countries

\section{Giriş}

Dışa açık bir ekonomide cari işlemler dengesi bir ülkenin toplam üretimi ile toplam harcamaları arasındaki fark olarak tanımlanır. Açık bir ekonomide, eğer bir ülkenin toplam üretimi harcamalarından az olursa, cari işlemler açık verecektir. Cari işlemler açığının sürdürülebilir düzeyde olması, ülke ekonomisinin dış şoklara karşı dayanıklılığı açısından son derece önemlidir. Ekonomik literatürde açık sorunu farklı bir bakış açısıyla incelenmektedir. İktisatçılar zamanın her hangi bir noktasındaki açığın büyüklügü yerine, açık sorununu yükümlülüklerin hali hazır değerini ölçen zamanlararası geri ödeme yeteneği

Doç. Dr. Sabri Azgün, Atatürk Üniversitesi, sabriazgun@atauni.edu.tr 
koşulu ile belirlemektedirler. Esasen geri ödeme yeteneği koşulu, cari ekonomi politikasının hali hazır değer borçlanma kısıtının dikkate alınarak yürütülmesi olayıdır.

Cari işlemler açığının sürdürülebilirliği zamanlararası bütçe kısıtı (veya zamanlararası geri ödeme yeteneği koşulu) tarafından belirlenmektedir. Söz konusu kısıta göre, hali hazır değer terimlerinde, ifade edilen cari ve beklenen faiz dışı dış aleme yapılan harcamaların toplamı, iskonto edilmiş dış alemden elde edilen gelirlerin toplamını aşmamalıdır. Bu bağlamda zamanlararası dış bütçe kısıtını (veya geri ödeme yeteneği koşulunu) faiz dışı dış âlemden elde edilen gelirlerle dış aleme yapılan harcamaların izleyeceği yol belirlemektedir. Bu iki değişken uzun dönem denge ilişkisi içerisinde değillerse, zamanlararası dış bütçe kısıtı sağlanmamış olacaktır.

Kamu sektörü zamanlararası bütçe kısıtı ve cari işlemler diş bütçe kısıtı ile ilgili geniş bir literatür mevcuttur. Zamanlararası borçlanma kısıtı olarak adlandırılabilecek söz konusu kısıt, hükümet açık bütçe politikası uyguladığında veya cari işlemler açık verdiğinde, uygulanan cari hükümet politikasının birikmiş kamu ve diş borç ve faizlerini ödemek için yeteri kadar bütçe fazlası veya dış fazla verip vermeyeceğinin teknik ölçütüdür. Söz konusu kısıta ilişkin temel çalışmalar Hamilton ve Flavin (1986), Wilcox (1988), Trehan and Walsh (1991), Hakkio ve Rush (1991) tarafindan yapılmıştır. Bu çalışmaların önermelerini esas alarak Baglini ve Cherubini (1993), Tanner (1994), Ahmet ve Rogers (1995), Caparole (1995), Bohn (1998), zamanlararası bütçe kısıtı kuramını muhtelif ülkelerin kamu açıklarına ve cari işlemler açıklarına uygulamışlardır. Azgun (2009) ve Binatli ve Sohraji (2012) zamanlararası borçlanma kısıtı koşulunu Türkiye için araştırmışlardır.

Bu çalışmada, 1990'lı yıllarda Sovyetler Birliğinden ayrılarak bağımsızlığına kavuşan Orta Asya Türk ekonomilerinden Azerbaycan, Kazakistan, Kırg1zistan, Türkmenistan, Özbekistan ve Türkiye ekonomilerinde zamanlararası bütçe kısıtının sağlanıp sağlanmadığı araştırılmaktadır. Zira bu ekonomilerin bağımsızlıklarına kavuştuktan sonra, sürdürülebilir bir ekonomik yapı oluşturup, oluşturamadıklarının belirlenmesi açısından temel göstergelerinden birisi cari işlemler açıklarıdır. Zira cari işlemler hesabının sürekli olarak açı vermesi ülkenin üretim olanaklarının ötesinde bir yaşam sürdürmesi anlamına da gelecektir. Bu da ekonomik bağımsızlığın yitirilmesi sonucunu doğuracaktır.

\section{Zamanlararası Bütçe Kısıtı}

Bu kesimde, zamanlararası dış bütçe kısıtı her hangi bir ülke için tanımlanmakta ve cari işlemler açığı için geri ödeme yeteneği koşulu matematiksel olarak tartışılmaktadır. Hükümet her dönem için bir dış bütçe kısıtı ile karşı karşıya kalmaktadır. Hükümetin karşılaştığı bütçe kısıtı aşağıdaki gibi ifade edilebilir.

$$
d e_{t}+(1+r) f_{t-1}=c r_{t}+f_{t}
$$

Yukarıdaki eşitlikte $f_{t}$ hükümetin ilgili dönemde dış piyasadan fon sağlamak için ihraç ettiği borç senet-

lerini tanımlamaktadır. de $e_{t}$ hükütmetin mal hizmet alımları için dış dünyaya yaptığı harcamalar ile dış

dünyaya yapılan transferleri göstermektedir. $c r_{t}$ mal ve hizmet ihracı yoluyla diş dünyadan elde edilen gelirler ile dış aleme sağlanan transferleri göstermektedir.

$r_{t}$ ise $\mathrm{t}$ dönemindeki reel faiz oranını ifade eder. Eşitlik (1) ile verilen matematiksel eşitliğin sol tarafı hükümetin $t$ dönemi boyunca diş âleme yaptığı harcamaları ifade ederken, eşitliğin sağ tarafı hükümetin aynı dönemdeki dış alemden elde ettiği gelirini göstermektedir. Hükümetin her hangi bir $\mathrm{t}$ döneminde karşı karşıya olduğu zamanlararası diş bütçe kısıtını ifade eden (1) nolu eşitlikteki değişkenler nominal veya reel terimler cinsinden de ifade edilebilir. Eşitlik (1)'in sol tarafındaki ikinci terim dış dünyaya yapılan borç servisini gösterirken, söz konusu eşitliğin sağ tarafındaki ikinci terim borçlanmalar yoluyla dış dünyadan elde edilen gelirleri göstermektedir.

Eşitlik (1) de t dönemi için ifade edilen bütçe kısıtı bütün $\mathrm{t} i+(1,2,) \mathrm{i}=\mathrm{L}$ dönemleri için geçerlidir. $\mathrm{Bu}$ ifade $t+1, t+2, t+3 \ldots$ Dönemleri için ileriye doğru çözülürse, zamanlararası dış bütçe kısıtı elde edilir:

$$
f_{t}=\sum_{t=1}^{\infty} r_{t}\left(c r_{t}-d e_{t}\right)+\lim _{n \rightarrow \infty}\left(r_{n} f_{n}\right)
$$


Eşitlik (2)'de $r_{t}=\prod_{s-t}^{t} f_{s} \quad$ ve $f_{s}=1 / 1+f_{s}$ olarak tanımlamaktadır. Eşitlik (2) ile tanımlanan zamanlararası dış bütçe kısıtındaki en önemli unsur eşitliğin sağ tarafındaki $\lim _{n \rightarrow \infty}\left(r_{r} f_{n}\right)$ olarak ifade edilen en son terimdir. Bu terin sıfıra yakınsadığında, bir başka ifadeyle $\lim _{n \rightarrow \infty}\left(r_{r} f_{n}\right)=0$ olduğunda, zamanlararası dış borçlanma kısıtı tatmin edilmiş olur. Zamanlararası bütçe kısıtı; borç senetleri stokunun, cari işlemler fazlalarının hali hazır değerine eşit olduğunu ifade eder. Bu limitin sıfır olmaması, hükümetin cari işlemler açı̆̆ını yeni borç senedi ihraç ederek finanse ettiği anlamına gelmektedir. Hükümetin "Ponzi finansı" olarak adlandırılan bu durumu uzun süre devam ettirebilmesi mümkün değildir. Diğer bir ifade dış borçlar reel faiz oranından daha büyük bir oranda sonsuza kadar büyüyemez. Cari ekonomik politikanın sürdürülebilir olup olmadığı benzer politikanın uygulandığı dönemler esas al1narak, hali hazırda ve yakın gelecekte cari hükümet ekonomi politikasının sürdürülebilir yolda olup olmadığı belirlenmeye çalışılır. Böylece belirli bir ekonomi politikasının uygulandığı dönemin verileri ile $\lim _{n \rightarrow \infty}\left(r_{r} f_{n}\right)=0$ koşulunun sağlanıp sağlanmadı̆̆ araştırılır. $c r_{t}$ ve $d e_{t}$ değişkenlerinin stokastik süreçler oldukları varsayılırsa, sürdürülebilirlik için limit ifadesinin beklenen değerinin sıfıra eşit olması gerekir. Diğer bir ifade ile $E\left[\lim _{n \rightarrow \infty}\left(r_{n} f_{n}\right)\right]$ koşulunun sağlanması, hem cari ekonomik politikanın ve hem de cari işlemler açılarının sürdürülebilir olduğunun bir göstergesidir.

Dış açılkar itibariyle zamanlararası geri ödeme yeteneği veya borçlanma koşulu, Eşitlik (2)'deki gibi ifade edilmekle birlikte, bu ifade cari işlemler açıklarının ekonometrik analizi için kullanılamaz. Ancak, eşitlik (2) ile tanımlanan matematiksel ifadeyi ekonometrik olarak test edilebilir forma dönüştürmek mümkün-

dür. Eşitlik (1)'in her iki tarafından $r f_{t-1}$ ifadesi ç1karılırsa, Eşitlik (3) elde edilir.

$$
d b_{t}+(1+r) f_{t-1}=c r_{t}+f_{t}
$$

Burada, $d b_{t}=d e_{t}+\left(i_{t}-i\right) f_{t} \quad$ bu ifade de faiz oranlarını durağan ve beklenen değerinin r'ye eşit olduğu varsayımı yapılmaktadır (Hamilton ve Flavin,

1986). Dolayısıyla, örtülü olarak $d e_{t}$ değişkeninin $d b_{t}$ değişkenine eşit olduğu varsayımı yapılmıştır. Eşitlik (3) bütün dönemler için geçerlidir. Eşitlik (3) birinci farklar cinsinden ifade edilirse, aşağıdaki eşitliğe ulaşılır.

$$
\Delta f_{t}=(1+r) f_{t-1}+\Delta d b_{t}-\Delta c r_{t}
$$

Eşitlik (4)'de $\Delta$ birinci farkları göstermektedir. Eşitlik (4), temel eşitlik olan Eşitlik (1)'in içerisine konulur ve ileriye doğru çözülerse, aşağıdaki ifadeye ulaşılır.

$d m_{t}=c r_{t}+\lim _{i \rightarrow \infty} \frac{\Delta f_{t+i}}{(1+r)^{i}}+\sum_{j=t+1}^{\infty} \frac{\Delta c r_{j}-d b_{j}}{(1+r)^{j-t}}$

Yapılan ampirik çalışmalar $c r_{t}$ ve $d b_{t}$ değişkenlerinin birikimli rassal yürüyüş süreci (random walks with dirft) izlediklerini göstermektedir:

$$
\begin{aligned}
& c r_{t}=a_{1}+c r_{t-1}+u_{1+t} \\
& d e_{t}=a_{2}+d e_{t-1}+u_{2+t}
\end{aligned}
$$

Bu durumda Eşitlik (15) aşağıdaki gibi yeniden ifade edilir:

$$
\begin{aligned}
d e_{t}= & c r_{t}+\lim _{n \rightarrow \infty} \frac{\Delta f_{t-j}}{(1+r)^{j}}+\frac{a_{1}+a_{2}}{r}+ \\
& \cdot \sum_{j=t+1}^{\infty} \frac{\left(u_{1 t}-u_{2 t}\right)}{(1+r)^{j-t}}
\end{aligned}
$$

Eşitlik (6) test edilecek hipotezin matematiksel ifadesidir. Cari işlemler açığı için geri ödeme yeteneğinin sağlandığı durumda, eşitliğin sağ tarafındaki terimin sıfıra yakınsadığı varsayılır. Çünkü. Böyle bir varsayımın yapılmaması durumunda sonsuza kadar borcun borçla çevrilebileceği şeklinde bir durum ortaya çıar. Böyle bir durum, rasyonel davranan İktisadi birimlerin (borç verenler ve borç alanlar) çıkarları ile bağdaşmaz. Zamanlar arası dış borçlanma kısıtının sağlandığı Kabul edilirse, Eşitlik (6) aşağıdaki gibi yazılır: 
$c r_{t}=a_{t}+b d m_{t}+\iota_{1}$

Eşitlik (7)'deki $c r_{t}$ ve $d b_{t}$ değişkenlerinin uzun dönemdeki denge ilişkisi, sürdürülebilirlik ilişkisini ifade etmektedir.

\section{Ekonometrik Yöntem}

Eşitllik (7) deki değişkenlerin eş bütünleşmesi, uzun dönemde, zamanlarası borçlanma kısıtının sağlandı$\breve{g}_{1}$ anlamına gelir. Diğer yandan, dm değişkenin modelde bağımsız değişken olarak yer alması merkezi hükümetlerde bütçeler hazırlanırken, harcamaların gelirlerden daha öncelikli olması şeklinde yorumlanmalıdır. Çalışmamızda ARDL Sınır Testi yaklaşımı kullanılacaktır. Eşitlik (7) ile tanımlanan dış borçlanma fonksiyonundaki değişkenler arasında eş bütünleşme ilişkisini test etmek için, (Johansen, 1998) ve iki adımlı Engle-Granger (1987) gibi muhtelif eşbütünleşme testleri kullanılabilir. Johansen yönteminin en büyük avantajı, eş-bütünleşme ilişkisinin mevcut olduğu çok sayıda vektörün tahmin edilmesine olanak sağlamasıdır. Bununla birlikte, Johansen uygulaması, açıklayıcı değişkenlerin tamamının birinci sıradan bütünleşik olduğunu baştan varsaymaktadır. Durağan ve birim kök içeren serilerin birlikte mevcut olduğu durumda, geleneksel olabilirlik oran testleri üzerine dayalı standart istatistiksel yorum artık geçerli değildir ve johansen yaklaşımı hatalı yorumlara yol açabilir (Pesaran ve Shin, 1999). (Pesaran ve Shin, 1999) analize konu olan serilerin I(0), I(1) olup olmadığına dikkat etmeksizin eş-bütünleşme ilişkisinin varlığını test etmek için uygulanabilen bir ARDL sınır testi yaklaşımını geliştirmiştir. Bu yaklaşım, bir tipik Johansen çatısında açıklayıcı değişkenlerin I(0) ve I(1) olması durumunda karşılaşılan sorunların üstesinden gelirken, ARDL çatısını iyileştirmektedir.

Bir ARDL yaklaşımı açıklayıcı değişkenlerin, eş-anlı ve gecikmeli değerlerini ve açıllanan değişkenin gecikmeli değerlerini kullanan bir genel dinamik tahmindir. ARDL ile kısa dönemli etkiler doğrudan ve uzun dönemli etkiler dolaylı olarak tahmin edilebilir. Pesaran and Shin (1999) ARDL tahmini kapsaminda kullanılabilen eş-bütünleşme için sınır testini takdim etmektedir. Bu yöntem diğer eş-bütünleşme yöntemleri ile karşılaştırıldığında önemli avantajlara sahiptir. Çünkü ARDL tahmini değişkenlerin kesirli olarak eş-bütünleşik veya I(0) ve I(1) olup olmad1ğına bakılmaksızın kullanılabilir. Böylece, sınır testi bütünleşme sırasının ön-testi ile ilişkili belirsizliği ortadan kaldırmaktadır. İkinci olarak, ARDL tahmini küçük örnekler için kullanılabilir. Halbuki, Johansen ve Engle-Granger yöntemleri oldukça küçük örnekler için güvenilir değildir (Narayan, 2004).

ARDL yaklaşımı uzun dönem ilişkisini tahmin etmek için iki adım ihtiva eder. Birinci adım inceleme altındaki eşitlikteki bütün değişkenler arasında bir uzun dönem ilişkisinin varlığını incelemektir. Söz konusu değişkenler arasında eş-bütünleşme ilişkisi teyit edilirse, ikinci safhada, uzun dönem ve kısa dönem katsayıları ARDL ve ECM yaklaşımları kullanılarak tahmin edilebilir. Eş-bütünleşme ilişkisini test etmek için aşağıdaki şartlı kısıtsız hata düzeltme modeli (UECM) inşa edilir:

$$
\begin{aligned}
& \Delta d m_{t}=\alpha+\sum_{i=0}^{m} \beta_{i} \Delta c r_{t-i}+\sum_{i=0}^{k} \phi_{i} \Delta d m_{t-i}+ \\
& \eta_{1} \log c r_{t-1}+\eta_{2} d m_{t-1}+\varepsilon_{t}
\end{aligned}
$$

Burada, $\Delta$ birinci farkı göstermektedir. Eşbütünleşme eşitliği aşağıdaki gibi tanımlanır.

$$
\eta_{1} c r_{t-1}+\eta_{2} d m_{t-1}=0
$$

Sınır testi metodolojisi, Wald veya F- istatistiğine dayalı $c r_{t-1}$, ve $d m_{t-1}$ gecikmeli değişkenlerinin müşterek testi yoluyla hiçbir eş-bütünleşme ilişkisinin olmadığı boş hipotezini incelemeyi ima etmektedir:

$$
\begin{aligned}
& H_{o}: \eta_{1}=\eta_{2}=0 \\
& H_{1}: \eta_{1} \neq \eta_{2} \neq 0
\end{aligned}
$$

Pesaran ve Shin (1999)'e göre değişkenlerin bütünleşme derecesine bakılmaksızın ve hiç bir eşbütünleşmenin olmadığ edilen F- istatistiğinin asimptotik dağılımı standart değildir. Bu ARDL modelinde ihtiva edilen değişkenlerin I(0) veya I(1) olup olmadığına, bağımsız değişkenlerin sayısına, ARDL modelinin sabit ve/ veya trend ve örneklem hacmine bağlıdır. Alt sınır ve üst sinırları gösteren Kritik F-değerlerinin iki seti, büyük örnekler için Pesaran ve Shin (1999) tarafından sağlanmaktadır. Narayan (2004) 30-80 arasında değişen örnek hacmi için kritik F- değerleri takdim etmektedir. Eğer seçilen önem düzeyi için hesapla- 
nan F-istatistiği kritik sınırların dışına düşerse, değișkenlerin eş-bütünleşmesi ile ilgili kesin bir karar verilebilir. Eğer istatistik üst sınırdan daha yüksek ise hiçbir eş-bütünleşmenin olmadığı boş hipotez reddedilebilir.

\section{Analiz}

Çalışmada Azerbaycan, Kırgızistan, Kazakistan ve Türkiye Ekonomileri cari işlemler açıkları açısından analiz edilmektedir. Analizde 2005Q1-2014Q4 dönemi çeyrek yıllık verilerle test edilmektedir. $\mathrm{cr}$ ve de sırasıyla cari işlemler dengesinin gelir ve har- camalarını ifade etmektedir. Ülkelerin uluslararası plaka kodları ilgili değișkenlerin (cr ve de) başına eklenerek ilgili tanımlanmaktadır. Veriler IMF'den alınmıştır. Türkmenistan ve Özbekistan verileri bulunamadığından bu ülkelerin cari işlemler hesabı incelenememektedir.

Değişkenlerin birim test istatistik sonuçları Tablo l'de analiz edilmiştir. Türkiye'nin cari işler gider değişkeni hariç diğer bütün ülkelerin cari işlemler gelir ve harcama değişkenleri, düzey değerlerinde durağan değilken, birinci farklarında, durağan hale gelmektedir. Dolayısıyla Türkiye Hariç bu ülkeler için analiz de Johansen bütünleşme testi uygulanabilir. Johansen Eş bütünleşme test sonuçları, Tablo 2'de özetlenmiştir.

Tablo 1. ADF Birim Kök Testleri

\begin{tabular}{|l|l|l|l|}
\hline Değişken & ADF Test İstatistiği & Kritik Değerler (\%5) & C,T,L (SIC) \\
\hline LCRAZ & -2.430778 & -3.533083 & C, T, 1 \\
\hline LDEAZ & -3.167469 & -3.529758 & C, T,0 \\
\hline DCRAZ & -5.736448 & -3.536601 & C,T, 1 \\
\hline DDEAZ & -6.550621 & -3.533083 & C,T, 0 \\
\hline LCRKZ & -2.749032 & -3.452358 & C, T,0 \\
\hline LDEKZ & -2.723183 & -3.454032 & C,T, 3 \\
\hline DCRKZ & -10.39548 & -3.452764 & C,T, 0 \\
\hline DDEKZ & -10.39690 & -3.452764 & C,T, 0 \\
\hline LCRKS & -2.450454 & -3.557759 & C,T, 4 \\
\hline LDEKS & -3.169725 & -3.557759 & C,T, 4 \\
\hline DCRKS & -9.949247 & -3.552973 & C,T, 2 \\
\hline DDEKS & -6.562851 & -3.557759 & C,T, 2 \\
\hline LCRTR & -3.378102 & -3.544284 & C,T,4 \\
\hline LDETR & -3.965468 & -3.544284 & C,T,4 \\
\hline DCRTR & -9.407459 & -3.536601 & C,T,1 \\
\hline DDETR & -5.380098 & -3.533083 & C,T,2 \\
\hline
\end{tabular}

Tablo 2. Johansen Eșbütünleșme Test Sonuçları

\begin{tabular}{|l|l|l|l|}
\hline Değişkenler & Trace Değeri & $\begin{array}{l}\text { Kritik Değer } \\
(\% 5)\end{array}$ & Eş bütünleşme \\
\hline LCRAZ -LDEAZ & 12.59541 & 15.49471 & Yok \\
\hline LCRKZ- LCRKZ & 21.80274 & 15.49471 & Var \\
\hline LCRKS- LDEKS & 18.10720 & 15.49471 & Var \\
\hline
\end{tabular}


Tablo 3. ARDL Sınır Testi Özet İstatistikleri

\begin{tabular}{|l|l|l|l|l|l|}
\hline Ülke & Trend & Hesaplanan F & \multicolumn{4}{l|}{ Kritik Değerler } \\
\hline & & & $\% 10$ & $\% 5$ & $\% 1$ \\
\hline AZ & Yok & 5.72 & $4,04-4,78$ & $4,94-5,73$ & $6,84-7,84$ \\
\hline AZ & Var & 3.67 & $5,59-6,26$ & $6,56-7,30$ & $8,74-9,63$ \\
\hline KZ & Yok & 5,04 & $4,04-4,78$ & $4,94-5,73$ & $6,84-7,84$ \\
\hline KZ & Var & 5,25 & $5,59-6,26$ & $6,56-7,30$ & $8,74-9,63$ \\
\hline KS & Yok & 6.66 & $4,04-4,78$ & $4,94-5,73$ & $6,84-7,84$ \\
\hline KS & Var & 4.28 & $5,59-6,26$ & $6,56-7,30$ & $8,74-9,63$ \\
\hline TR & Yok & 5.15 & $4,04-4,78$ & $4,94-5,73$ & $6,84-7,84$ \\
\hline TR & Var & 4.92 & $5,59-6,26$ & $6,56-7,30$ & $8,74-9,63$ \\
\hline
\end{tabular}

Elde edilen sonuçlara göre Azerbaycan için CR ve DE değişkenleri arasında uzun dönem denge ilişkisi bulunmazken, Kazakistan ve Kırgızistan için CR ve DE değişkenleri arasından uzun denge ilişkisi içerisindedir.

Söz konusu analiz ARDL Sınır testi yardımıyla yapılmıştır. Analiz sonuçları Tablo 3'de özetlenmiştir. Trend değişkeninin modele dahil edilemediği, sadece $\% 10$ önem düzeyinde, Azerbaycan, Kazakistan, Kırgızistan ve Türkiye için cr ve de değişkenleri arasında eș bütünleşme ilişkisi bulunmaktadır. \%5 önem düzeyinde Azerbaycan için eş bütünleşme ilişkisi yok, Kazakistan kararsızlık bölgesinde, Kırgızistan için eş bütünleşme ilişkisi yok, Türkiye kararsızlık bölgesinde, Trend değişkeninin modele dahil edildiği durumda hiç bir ülke için eş bütünleşme ilişkisi bulunmamaktadır.

\section{Sonuç}

Azerbaycan, Türkmenistan, Özbekistan, Kırgızistan, Kazakistan ülkeleri 1990'lı yıllarda Sovyetler Birliği’nin dağılmasıyla birlikte bağımsızlıklarına kavuşmuşlardır. Söz konusu ülkeler ekonomik kurumlarını oluşturmaları ile birlikte uluslararası ekonomik kuruluşlara üye olmuşlardır. Bu çalışmada Orta Asya Türk cumhuriyetleri cari işlemler açıkları sürdürülebilirlik açısından analiz edilmişlerdir. Özbekistan ve Türkmenistan ekonomileri için veri bulunamad1ğından bu ülkeler cari işlemler açısından değerlendirilememiştir. Cari işlemler açığı bir ülkenin yurt içi üretimi ile harcamaları arasındaki farka bağlı olarak ortaya çıkmaktadır. Eğer bir ülkenin üretimi harcamalarından azsa cari işlemler hesabı açık verecektir. $\mathrm{Bu}$ noktada cari işlemler açığının sürdürülebilirliği önem kazanmaktadır. Cari işlemler hesabının sürdürülebilirliği, cari ekonomi politikasının da sürdürülebilirliğinin bir göstergesidir. Diğer yandan, bu ülkeler açısından cari işlemlerinin sürdürülebilirliği, ülkelerin kurumsal bir yönetim oluşturup oluşturamadıklarının bir göstergesi olarak değerlendirilebilir. Zamanlarası borçlanma kısıtı, orta Asya Türk Cumhuriyetleri ve Türkiye için Johansen eş bütünleşme ve sınır testi yaklaşımları ile analiz edilmiştir. Söz konusu ülkeler için analiz sonuçları değerlendirildiğinde, her iki test itibariyle hiçbir ülke \%5 önem düzeyinde zamanlararası borçlanma kısıtı koşulunu sağlayamamaktadır. Kazakistan ve Kırgızistan \%5 önem düzeyinde Johansen eş-bütünleşme testine göre, zamanlararası geri ödeme yeteneği koşulunu sağlarken, Sınır Testi yaklaşımında sadece trend değişkeninin dahil edilmediği durumda \%10 önem düzeyin cari işlemler disiplini açısından sorun ortaya çıkmadığı söylenebilir. Genel olarak değerlendirildiğinde, ülkelerin cari işlemler açıklarının sürdürülemez boyutlarda olduğu söylenemez. Ancak, bu ülkelerin genç ülkeler olması, ihracat mallarının ağırlıklı olarak doğal gaz ve petrole dayalı olması ve ithalat olarak sermaye malları ve teknoloji ürünleri açısından dışa bağımlı olmaları nedeniyle, dış ticaret politikasının cari işlemeler dengesinde sıkıntı yaratmayacak şekilde düzenlemesi son derece önemlidir. 


\section{Kaynakça}

Ahmed, S., Rogers, J. H. (1995). Government Budget Deficits and Trade Deficits Are Present Value Constraints Satisfied in Long-Term Data?. Journal of Monetary Economics, 36(2), 351-374.

Azgun, S. (2009). Is Current Account Deficit 'Too Large': Some Further Evidence. Trakia Journal of Sciences, 7(3), 51-56.

Baglioni, A., Cherubini, U. (1993). Intertemporal Budget Constraints and Public Debt Sustainability: The case of Italy. Applied Econometrics, 25(2), 275-283.

Binatl, A.O., Sohrabji, N.(2012). Intertemporal Solvency of Turkey's Current Account. Panoeconomicus, 59(1), 89-104.

Bohn, H. (1998). The Behavior of U.S. Deficits Public Debt and Deficits. Quarterly Journal of Economics, 113 (3), 949-963.

Caparole, M. G. (1995). Bubble Finance and Debt Sustainability: a Test of the Government's Intertemporal Budget Constraint. Applied Econometrics, 27(12), 1135-1143.

Hakkio, C. S., Rush, M. (1991). Is the Budget Deficit 'Too Large?. Economic Inquiry, 29(3), 429-445.

Hamilton, J. D., Flavin, M. A. (1986). On the Limitations of Government Borrowing: A Framework for Empirical Testing. The American Economic Review, 76(4), 808-819.
Pesaran, M. H., Shin, Y. Smith, R. J.(2001). Bounds Testıng Approaches To The Analysis of Level Relationships. Journal of Applied Econometrics, 16(3), 289-326.

Quintos, C. E. (1995). Sustainability of Deficit Process with Structural Shifts. Journal of Business \& Economic Statistics, 13(4), 409- 417.

Tanner, E., Liu P. (1994). The Budget Deficit 'Too Large' Some Further Evidence. Economic Inquiry, 32(3), 511-518.

Trehan, B., C. E. Walsh (1991). Testing Intertemporal Budget Constraints: Theory and Applications to U.S. Federal Budget and Current Account Deficits. Journal of Money, Credit and Banking, 23(2), 206223.

Wickens, M.R., Uctum M. (1993). The Sustainability of Current Account Deficits: A Test of The U.S. Intertemporal Budget Constraint. Journal of Economic Dynamic and Control, 17(3), 423-441.

Wilcox, D. W. (1989). The Sustainability of Government Deficits: Implications of the Present-Value Borrowing Constraint. Journal of Money, Credit and Banking, 21(3), 291-306. 